\title{
Subtyping Analysis of Fanconi Anemia by Immunoblotting and Retroviral Gene Transfer
}

\author{
Michael Pulsipher, ${ }^{1,2}$ Gary M. Kupfer, ${ }^{1,2}$ Dieter Naf, $^{1}$ \\ Ahmed Suliman, ${ }^{1}$ Jeng-Shin Lee, ${ }^{2}$ Petra Jakobs, ${ }^{4}$ \\ Markus Grompe, ${ }^{4}$ Hans Joenje,, ${ }^{5}$ Colin Sieff,,2 Eva Guinan, ${ }^{1,2}$ \\ Richard Mulligan, ${ }^{3}$ and Alan D. D'Andrea ${ }^{1,2}$ \\ ${ }^{1}$ Division of Pediatric Oncology, Dana-Farber Cancer Institute, Boston, \\ Massachusetts, U.S.A. \\ ${ }^{2}$ Department of Pediatrics, Children's Hospital, Harvard Medical \\ School, Boston, Massachusetts, U.S.A. \\ ${ }^{3}$ Department of Genetics, Howard Hughes Medical Institute, Harvard \\ Medical School, Boston, Massachusetts, U.S.A. \\ ${ }^{4}$ Department of Pediatrics, Oregon Health Sciences University, \\ Portland, Oregon, U.S.A. \\ ${ }^{5}$ Department of Human Genetics, Free University, Amsterdam, The \\ Netherlands \\ Communicated by D. Nathan. Accepted June 2, 1998.
}

\begin{abstract}
Fanconi anemia (FA) is an autosomal recessive cancer susceptibility syndrome with at least eight complementation groups $(\mathrm{A}-\mathrm{H})$. Two of the FA genes ( $F A A$ and $F A C)$ have been cloned, and mutations in these genes account for approximately $80 \%$ of FA patients. Subtyping of FA patients is an important first step toward identifying candidates for FA gene therapy. In the current study, we analyzed a reference group of 26 FA patients of known subtype. Most of the patients (18/26) were confirmed as either type $A$ or type $C$ by immunoblot analysis with
\end{abstract}

anti-FAA and anti-FAC antisera. In order to resolve the subtype of the remaining patients, we generated retroviral constructs expressing FAA and FAC for transduction of FA cell lines (pMMP-FAA and pMMP-FAC). The pMMP-FAA construct specifically complemented the abnormal phenotype of cell lines from FA-A patients, while pMMP-FAC complemented FA-C cells. In summary, the combination of immunoblot analysis and retroviral-mediated phenotypic correction of FA cells allows a rapid method of FA subtyping.

\section{Introduction}

Fanconi anemia (FA) is an autosomal recessive disease characterized by developmental abnormalities, bone marrow failure, and cancer susceptibility $(1,2)$. The mean survival of FA pa-

Address correspondence and reprint requests to: Dr. Alan D. D'Andrea, Division of Pediatric Oncology, Dana-Farber Cancer Institute, 44 Binney Street, Mayer Building, Room 640, Boston, MA 02115, U.S.A. Phone: (617) 632-2112; Fax: (617) 632-2085; E-mail: a_dandrea@farber.harvard.edu tients is 16 years, and death usually results from complications of bone marrow failure (3). The preferred treatment for bone marrow failure in FA is HLA-matched related allogeneic bone marrow transplantation. Transplantation can result in long-term marrow recovery, but most FA patients do not have matched donors (4-6). Gene therapy (7), using one of the two cloned FA cDNAs ( $F A A$ and $F A C)(8-10)$, offers an alternative strategy for FA treatment, but it requires 
prior knowledge of the patient's complementation group. Functional retroviruses for the $F A A$ cDNA (11) and the FAC cDNA (7) have recently been described.

Diagnosis of FA exploits the sensitivity of FA cells to the bifunctional alkylating agents mitomycin $C$ (MMC) and diepoxybutane (DEB). Analysis of DEB-induced chromosomal breakage provides a highly sensitive and specific diagnostic test for new patient and prenatal screening (12-15), but it does not distinguish among the known complementation groups of FA. Screening methods have been developed for the relatively small number of $F A C$ mutant alleles, allowing identification of the great majority of FA-C patients $(16,17)$. In contrast, the $F A A$ gene has a large number of different mutant alleles that have been described, rendering genotypic analysis less practical for screening new FA patients $(9,10,18)$.

Definitive complementation group subtyping of FA patients has traditionally involved somatic cell fusion studies of patient cells with index cells of known complementation groups (19-21). These studies allowed the identification of at least eight complementation groups of FA (19-21), leading to the cloning of the $F A A$ and $F A C$ genes $(8-10)$ and to the mapping of the $F A D$ gene (22). FA-A and FA-C account for approximately $66 \%$ and $13 \%$ of FA patients, respectively (19-21). Since subtyping by somatic cell fusion is generally slow and laborious, newer approaches using the cloned FA genes would be advantageous.

In the current study, we used a combination of immunoblot analysis, with newly available anti-FAA and anti-FAC antisera, and retroviral infection to confirm the subtype of 26 FA patients as either FA-A, FA-C, or non-A,C. These newly generated retroviral constructs are therefore useful in establishing FA subtype and may serve as important tools for future FA gene therapy trials.

\section{Materials and Methods}

\section{Cell Culture}

Epstein-Barr virus (EBV)-transformed lymphoblasts derived from FA patients were maintained in suspension culture in RPMI 1640 medium supplemented with $15 \%$ heat-inactivated fetal calf serum (FCS) and grown in a humidified 5\% $\mathrm{CO}_{2}$-containing atmosphere at $37^{\circ} \mathrm{C}(23)$. SV40transformed fibroblast lines or primary fibro- blasts derived from FA patients were grown as monolayer cultures in DMEM medium with $15 \%$ FCS.

\section{Cloning of FAA and FAC into the PMMP Vector}

The $F A A$ cDNA $(4.3 \mathrm{~kb})(9)$ and $F A C$ cDNA (1.8 $\mathrm{kb})(8)$ were cloned into the retroviral vector, pMMP. pMMP is a MFG-based vector with modifications from the MPSV (24) and PBSQ (25) vector systems. We subcloned the open reading frame of the $F A A$ cDNA into the $N c o$ I/ BamHI site of pMMP using fragments purified from the pREP4-FAA cDNA. The NcoI site overlapped the ATG start site of FAA translation initiation. The FAC cDNA was cut from the pREP4-FAC construct (8) and blunt end ligated into the BamHI site of pMMP. Preservation of the $N c o$ I site allowed a start site $112 \mathrm{bp} 5^{\prime}$ of the FAC start site, resulting in translation of a normal FAC protein and a longer form of the FAC protein containing an additional 16 amino acids at the amino terminus. Essential regions of pMMP-FAA and pMMP-FAC were confirmed by sequence analysis.

\section{Retroviral Infection of FA Cell Lines}

pMMP-FAA, pMMP-FAC, or pMMP-nlsLacZ (26) plasmids were transfected by lipofection into 293-GPG packaging line and pseudotyped with the vesicular stomatitis virus (VSV-G) envelope protein (26). Supernatants were collected on days 4, 5, and 6 following lipofection and titered by assessing copy number integration in NIH-3T3 cells by Southern blot. Viral supernatant titers ranged from 2 to $5 \times 10^{6}$ infectious units $/ \mathrm{ml}(\mathrm{IU} / \mathrm{ml})$ and were used for fibroblast transduction. Retroviral supernatants used for EBV-transformed lymphoblast and human bone marrow transduction were concentrated by ultracentrifugation $\left(50,000 \times g\right.$ for $90 \mathrm{~min}$ at $\left.4^{\circ} \mathrm{C}\right)$ with resultant titers of $1-2 \times 10^{8} \mathrm{IU} / \mathrm{ml}$.

FA fibroblasts $\left(5 \times 10^{5}\right.$ cells $)$ were infected with retroviral supernatants for 4 to $6 \mathrm{hr}$ in the presence of $8 \mu \mathrm{g} / \mathrm{ml}$ polybrene (Sigma). FA lymphoblast transduction was performed on plates previously coated with recombinant fibronectin fragments (27) (a generous gift of Takara Shuzo Co., Japan). Concentrated retroviral supernatants $(0.1 \mathrm{ml})$ were added to $1 \times 10^{6}$ lymphoblasts in $0.4 \mathrm{ml}$ of RPMI plus $15 \%$ FCS for $6-12$ $\mathrm{hr}$ in the presence of $4 \mu \mathrm{g} / \mathrm{ml}$ polybrene. After 24-48 hr, cells were analyzed for MMC sensitivity or FAA protein expression. 


\section{Titering of Retroviral Supernatants}

Supernatants were titered by adding retroviral supernatant $(1 \mathrm{ml})$ to NIH-3T3 cells $\left(3 \times 10^{5}\right)$ in the presence of polybrene $(8 \mu \mathrm{g} / \mathrm{ml})$. The medium was changed after $4 \mathrm{hr}$, and the cells were grown to confluence. Cells were trypsinized and DNA isolated by the Puregene DNA isolation kit (Gentron). DNA $(10 \mu \mathrm{g})$ from each sample was run on $0.7 \%$ agarose gels alongside several lanes with control DNA spiked with plasmid amounts equivalent to known copy numbers. DNA was then transferred to a duralon membrane and UV cross-linked. The blot was probed with a ${ }^{32} \mathrm{P}$ labeled fragment $(588 \mathrm{bp})$ generated by PCR from the $F A A$ cDNA. Blots were scanned with the GS-525 Molecular Imaging System and quantitated by Molecular Analysis Software (BioRad, Hercules, CA).

\section{Mitomycin C Assay}

MMC sensitivity assays on lymphoblasts were performed as previously described $(23,28)$. MMC sensitivity assays for fibroblasts were performed by the G2 accumulation assay (see below).

\section{Immunoblot Analysis}

For immunoblotting, proteins from whole cell extracts were run on SDS-PAGE and transferred to nitrocellulose in transfer buffer (Tris $25 \mathrm{mM}$, glycine $200 \mathrm{mM}$ ) at $400 \mathrm{~mA}$ at $4^{\circ} \mathrm{C}$. Filters were blocked for $1 \mathrm{hr}$ in $5 \%$ bovine serum albumin (BSA) in TBS (50 mM Tris-HCl, pH 8.0, $150 \mathrm{mM}$ $\mathrm{NaCl}$ ) and incubated in primary antibody (either $\mathrm{N}$-terminal- or C-terminal-specific anti-FAA antisera or an $\mathrm{N}$-terminal-specific anti-FAC antiserum) in TBS plus $0.1 \%$ Tween 20 (TBS-T) at room temperature for $12 \mathrm{hr}$. These polyclonal antibodies were purified from rabbit serum after injecting HA-tagged amino- and carboxy-terminal sequences of FAA and FAC proteins and were shown to have specificity for FAA and FAC proteins compared with preimmune serum $(23,29)$. After extensive washing in TBS-T and exposure to horseradish peroxidase-protein $A$, enzyme-linked chemiluminescence (Amersham) was performed.

\section{Assay for Correction of G2 Accumulation}

Forty-eight hours after retroviral transduction of primary fibroblasts, MMC $(25 \mathrm{ng} / \mathrm{ml})$ was added to the culture dishes. Cells were cultured for an additional $48 \mathrm{hr}$ in MMC and correction of MMC sensitivity was assessed by the $\mathrm{G} 2$ accumulation assay (28). Briefly, cells were trypsinized, washed once in PBS, and resuspended in PBS $(1 \mathrm{ml})$. While gently vortexing, ice-cold $80 \%$ ethanol ( $1 \mathrm{ml}$ ) was added to the suspended cells and the mixture placed immediately on ice and incubated for $2 \mathrm{hr}$. After ethanol fixation, cells were washed in PBS and resuspended in $0.5 \mathrm{ml}$ of a solution containing $50 \mu \mathrm{g} / \mathrm{ml}$ RNase A and $0.7 \mu \mathrm{M}$ propidium iodide in PBS and incubated at room temperature for $30 \mathrm{~min}$. Approximately 10,000 cells were analyzed for fluorescence intensity by FACScan (Becton Dickinson). The percentage of cells in each phase of the cell cycle was determined by analysis with the computer program, ModfitLT.

\section{Results}

Screening of FA Cell Lines by Anti-FAA and AntiFAC Immunoblot Analysis

Table 1 summarizes the 26 FA cell lines in our reference group, consisting of 21 lymphoblast lines and 5 primary fibroblast lines. The group contains 16 FA-A lines, 6 FA-C lines, 1 FA-B line, 2 FA-D lines, and I FA-E line, as defined by somatic cell fusion and genetic studies (20,30-32).

We analyzed these cell lines by immunoblot with anti-FAA and anti-FAC antisera (Figs. 1, 2). Of the 16 FA-A cell lines evaluated, 13 had no detectable full-length FAA protein (Fig. 1A, lanes 10-23; Fig. 1B, lanes 3-6). Two of these FA-A lines expressed possible truncated FAA proteins (Fig. 1A, lanes 12 and 22). Therefore, the confirmation of cell lines as FA-A was obvious by immunoblot in $13 / 16(81 \%)$ of FA-A patients. Three of the sixteen known FA-A cell lines expressed full-length FAA protein (Fig. 1 A, lanes $10,13,14)$, presumably resulting from a missense mutation or a small deletion or insertion in the $F A A$ gene. Immunoblot analysis therefore did not allow definitive subtyping of these three FA-A patients.

Of the six FA-C cell lines analyzed, five had no detectable FAC protein (Fig. 1A, lanes 5, 6, 7; Fig. 1B, lanes 1, 2) and one line expressed a full-length mutant FAC protein (Fig. 1A, lane 3), as previously described (23). Since an antibody specific for the amino terminus of FAC was used for these studies, we did not detect the presence of a common smaller isoform of FAC, FRP-50, which results from an internal reinitiation at 
Table 1. Summary of subtyping analysis

\begin{tabular}{|c|c|c|c|c|c|c|}
\hline & \multirow[b]{2}{*}{ Cell Name } & \multirow[b]{2}{*}{$\begin{array}{c}\text { FA } \\
\text { Type }^{a}\end{array}$} & \multicolumn{2}{|c|}{ Immunoblot Results ${ }^{b}$} & \multicolumn{2}{|c|}{ Retroviral Transduction ${ }^{c}$} \\
\hline & & & $\begin{array}{c}\text { FAA } \\
\text { Protein }\end{array}$ & $\begin{array}{c}\text { FAC } \\
\text { Protein }\end{array}$ & $\begin{array}{c}\text { FAA } \\
\text { Corrected }\end{array}$ & $\begin{array}{c}\text { FAC } \\
\text { Corrected }\end{array}$ \\
\hline \multirow[t]{21}{*}{ Lymphoblasts } & HSC72 & A & - & + & + & - \\
\hline & HSC 536* & $\mathrm{C}$ & + & + & - & + \\
\hline & PD4510 & $\mathrm{C}$ & + & - & & \\
\hline & PD1 53 & $\mathrm{C}$ & + & - & & \\
\hline & PD4 & $\mathrm{C}$ & + & - & & \\
\hline & HSC62 & $\mathrm{D}$ & + & + & - & - \\
\hline & PD20 & $\mathrm{D}$ & + & + & - & - \\
\hline & PD36 & A & + & + & + & - \\
\hline & VU337 & A & - & + & & \\
\hline & VU373 & A & + & + & & \\
\hline & EUFA007 & A & + & + & + & - \\
\hline & EUFA275 & A & - & + & & \\
\hline & EUFA444 & A & - & + & & \\
\hline & EUFA445 & A & - & + & & \\
\hline & EUFA471 & A & - & + & & \\
\hline & PD9 & A & - & + & & \\
\hline & PD45 & A & - & + & & \\
\hline & PD56 & A & - & + & & \\
\hline & PD 113 & A & - & + & & \\
\hline & HSC 230 & B & + & + & & \\
\hline & EUFA130 & $\mathrm{E}$ & + & + & & \\
\hline \multirow[t]{5}{*}{ Fibroblasts } & PD426 & $\mathrm{C}$ & + & - & - & + \\
\hline & PD 123 & $\mathrm{C}$ & + & - & - & + \\
\hline & PD303 & A & - & + & + & - \\
\hline & PD320 & $\mathrm{A}$ & - & + & + & - \\
\hline & PD473 & $\mathrm{A}^{d}$ & - & + & + & - \\
\hline
\end{tabular}

${ }^{a}$ FA subtype was determined by somatic cell fusion or by direct genotype analysis (see text).

${ }^{b}$ Plus $(+)$ sign indicates the presence of full-length protein by immunoblot analysis. $\left(^{*}\right)$ HSC536 cells express a full-length FAC protein with a L554P mutation.

${ }^{c}$ Plus (+) sign indicates the correction of mitomycin C sensitivity by retroviral-mediated transduction. Correction of MMC sensitivity of lymphoblasts was measured by the XTT assay. Correction of MMC sensitivity of fibroblasts was measured by G2 accumulation. Minus (-) sign indicates no correction.

${ }^{d}$ This patient is listed as FA-A based on immunoblot analysis, correction of G2 accumulation, and increased bone marrow progenitor clonigenicity after gene transfer.

amino acid 55 (28). Therefore, the identification of cell lines as FA-C was obvious by immunoblot in $5 / 6(83 \%)$ FA-C patients. Interestingly, the FA-B, FA-D, and FA-E cell lines expressed fulllength FAA and FAC protein (Fig. 1A, lanes 8, 9; Fig. 2), suggesting that mutations in other FA genes do not affect the expression of the FAA and FAC protein in these cells.
Subtyping of FA Patients by Retroviral Gene Transfer

In order to determine the subtype of FA cell lines by functional complementation, we next generated retroviral vectors to transduce the $F A A$ or $F A C$ cDNA. To test the function of these retroviral vectors, we initially infected FA-A and FA-C 
A
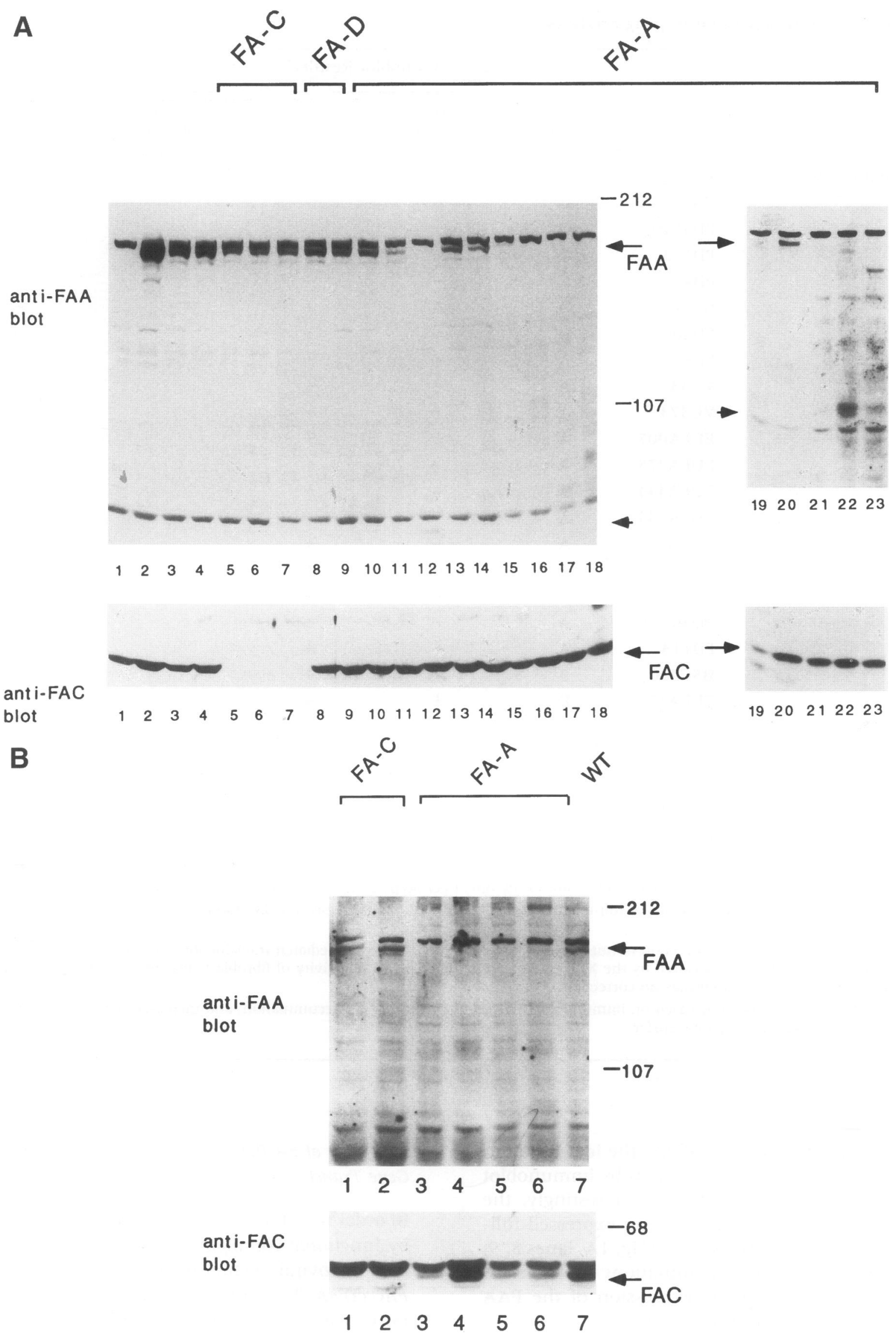
Fig. 1. Screening of Fanconi anemia lymphoblast and fibroblast lines for expression of FAA and FAC proteins. (A) EBV-immortalized lymphoblasts from FA patients were screened by immunoblot with either anti-FAA (upper blot) or anti-FAC (lower blot). Cell lines tested were HSC72 (lane 1), HSC72 after pMMP-FAA transduction (lane 2), HSC536 (lane 3), HSC536 after pREP4-FAC transfection (lane 4), PD4510 (lane 5), PD153 (lane 6), PD4 (lane 7), HSC62 (lane 8), PD20 (lane 9), PD36 (lanes 10,20 ), PD289 (an unknown type, not included in this analysis, presumed to be type $A$ on the basis of a truncation mutant detected with an anti-FAA carboxyl-terminal antibody, lane 11), VU 337 (lane 12), VU 373 (lane 13), EUFA 007 (lane 14), EUFA 275 (lane 15), EUFA 444 (lane 16), EUFA 445 (lane 17), EUFA 471 (lane 18), PD9, (lane 19), PD45 (lane 21), PD56 (lane 22), and PD113 (lane 23). Possible truncated FAA proteins were observed in lanes 12 and 22 (arrowheads). (B) Primary fibroblasts from FA patients were analyzed by immunoblot with either an anti-FAA antiserum (upper panel) or an anti-FAC antiserum (lower panel). Cell lines analyzed were PD426 (lane 1), PD123 (lane 2), PD303 (lane 3), PD320 (lane 4), PD473 (lane 5), PD289 (lane 6), and PD7 (normal control, lane 7). lymphoblast lines and assayed correction of MMC sensitivity (Fig. 3A). Transduction with the pMMP-FAA retroviral supernatant corrected the MMC sensitivity of FA-A (HSC72) cells, whereas pMMP-FAC retrovirus corrected the MMC sensitivity of FA-C (HSC536) cells. pMMP-FAA also corrected the MMC sensitivity of SV40 immortalized FA-A fibroblasts (GM6914), whereas pMMP-FAC did not (data not shown).

We next assayed FAA and FAC protein expression in retrovirally infected cell lines

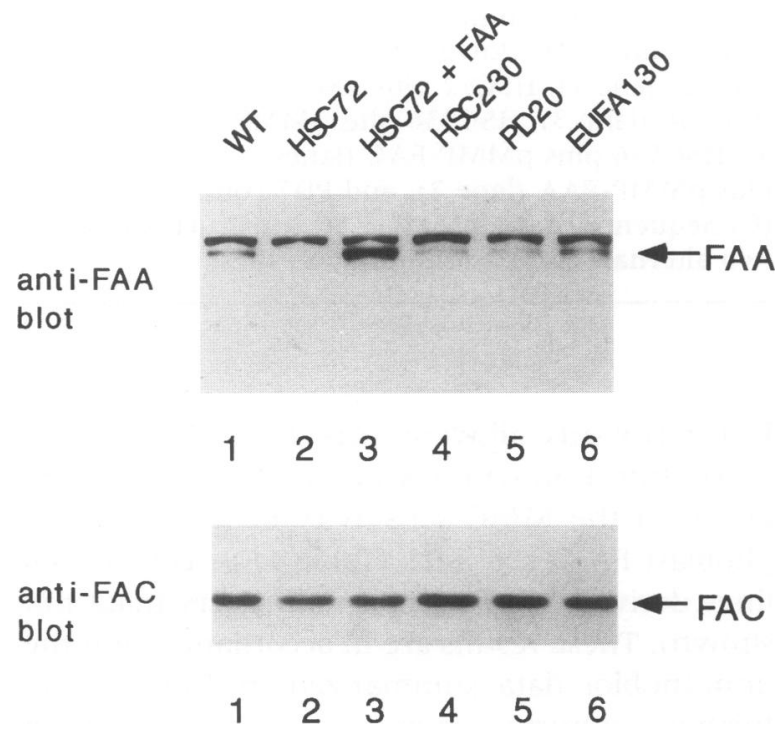

Fig. 2. Expression of FAA and FAC protein in FA-B, FA-D, and FA-E lymphoblast lines. Protein extracts from EBV-immortalized lymphoblasts were screened by immunoblot with either anti-FAA antiserum (upper blot) or anti-FAC antiserum (lower blot). Cell lines tested were wild-type lymphoblasts (PD7, lane 1), FA-A cells (HSC72) (lane 2), FA-A cells after pMMP-FAA transduction (lane 3), FA-B cells (HSC230) (lane 4), FA-D cells (PD20) (lane 5), or FA-E cells (EUFAl30) (lane 6).
(Fig. 3B). Parental HSC72 cells did not express detectable levels of FAA protein (lane 1), whereas HSC72 cells infected with pMMP-FAA expressed the FAA protein $(163 \mathrm{kD})$ (lane 2). Parental HSC536 cells expressed a full-length mutant FAC protein, FAC(L554P) (lanes 3, 4). HSC536 cells, infected with pMMP-FAC, expressed two bands of the FAC protein (FAC immunoblot, lanes 5,6$)$. The smaller form is the full-length FAC $(63 \mathrm{kD})$, which has the same electrophoretic mobility as the mutant FAC (L554P). The larger form of FAC (70 kD) contains an additional protein sequence at the $\mathrm{N}$ terminus resulting from fusion of the FAC open reading frame with a vector-derived sequence (Fig. 3C). Taken together, these experiments demonstrate that the retroviral vectors functionally correct FA cell lines and encode the FAA and FAC proteins in transduced cells.

We next analyzed several lymphoblast lines and primary skin fibroblasts, established from FA patients, by retroviral gene transfer. FA primary fibroblasts are sensitive to mitomycin $\mathrm{C}$ and accumulate in the G2/M phase of the cell cycle after MMC exposure $(33,34)$ (Fig. 4). An FA-A fibroblast line (PD320) accumulated to $59 \%$ in G2/M, after exposure to MMC (Fig. 4B). These same cells, infected with pMMP-FAA, accumulated to only $25 \% \mathrm{G} 2 / \mathrm{M}$ after MMC exposure (Fig. 4C), thereby demonstrating their functional complementation by FAA expression. Cells infected with pMMP-FAC or pMMP-nlsLacZ remained MMC sensitive, with G2/M accumulations of $51 \%$ and $56 \%$, respectively (Fig. $4 \mathrm{D}, \mathrm{E}$ ).

We next analyzed MMC-induced G2/M accumulation of five FA primary fibroblast cultures, after infection with either pMMP-FAA, pMMP-FAC, or pMMP-nlsLacZ retroviral supernatants (Fig. 5). Three FA-A fibroblast lines (PD320, PD303, and PD473) were specifically 

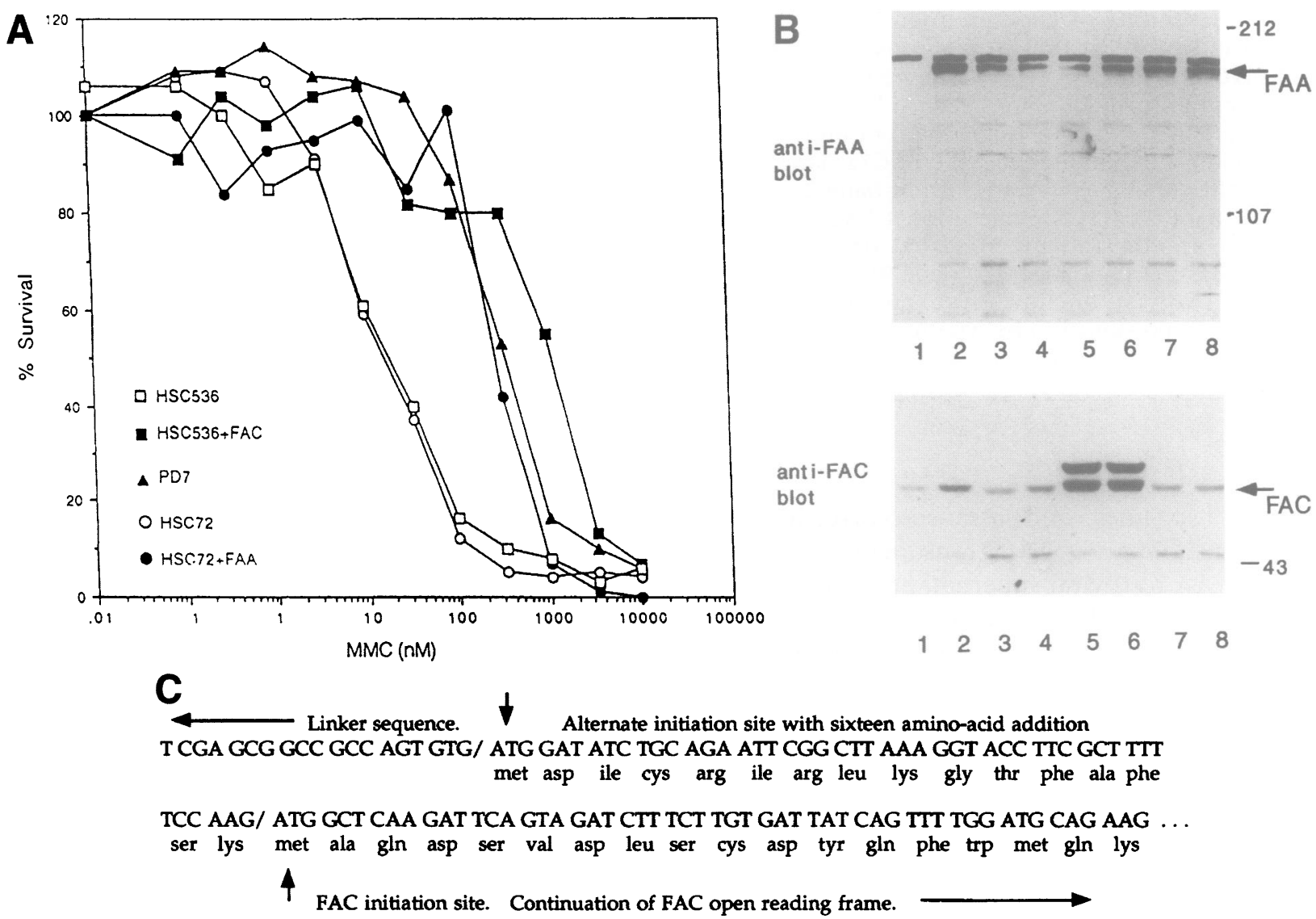

Fig. 3. Functional complementation of FA-A and FA-C cell lines with FAA and FAC retroviral supernatants. (A) The indicated FA lymphoblast lines were analyzed for MMC sensitivity. Cells shown include HSC72, HSC72 infected with pMMPFAA, HSC 536, HSC536 infected with pMMP-FAC, and PD7, a normal cell line. MMC sensitivity curves shown are representative of three separate retroviral infection experiments. (B) Infected FA lymphoblasts

corrected with the pMMP-FAA virus, but not with the pMMP-FAC virus or the pMMP-nlsLacZ virus. Two FA-C fibroblast lines (PD123 and PD426) were specifically corrected with the pMMP-FAC virus. Retroviral infection had no effect on G2/M accumulation of primary fibroblasts derived from normal, non-FA controls (Fig. 4, samples PD93-2 and PD138). Also, there was no improvement of $\mathrm{G} 2 / \mathrm{M}$ accumulation of primary fibroblasts from an FA-D patient after retroviral infection (data not shown).

In addition, several patient-derived lymphoblast lines were infected with FAA or FAC retroviral supernatants and assayed for correction of MMC sensitivity (Table 1). In total, of the six FA-A cell lines infected with the FAA retrovirus and the three FA-C cell lines infected with the were analyzed by immunoblot with anti-FAA (upper blot) or anti-FAC (lower blot). Cells analyzed were HSC72 (lane 1), HSC72 plus pMMP-FAA (lane 2), HSC536 (lane 3), HSC536 plus pMMP-nlsLacZ (lane 4), HSC536 plus pMMP-FAC (lanes 5, 6), HSC536 plus pMMP-FAA (lane 7), and PD7 control (lane 8). (C) Sequence of the pMMP-FAC construct, showing two alternate translation initiation sites.

FAC retrovirus, all were corrected to MMC resistance. Infection with FAA and FAC virus had no effect on the MMC sensitivity of the two lymphoblast FA-D cell lines (Table 1) or control cell lines derived from normal volunteers (data not shown). These results are in accordance with the immunoblot data summarized in Table 1 and further confirm previous complementation group assignment.

The EUFA007 cell line is particularly interesting (Table 1, Fig. 1A, lane 14). These cells are compound heterozygotes for the FAA gene $(\mathrm{H}$. Joenje, personal communication) and contain the mutant FAA allele 3788-3790del, which accounts for $5 \%$ of known FAA mutations (18). The full-length FAA protein expressed in these cells is therefore presumably the mutant, non- 
A. No MMC

B. + MMC

\section{PMMP-FAA} (+MMC)

D. PMMP-FAC (+MMC)

\section{E. pMMP-nlsLacZ (+MMC)}

\section{$2 \mathrm{~N} \quad 4 \mathbf{N}$}
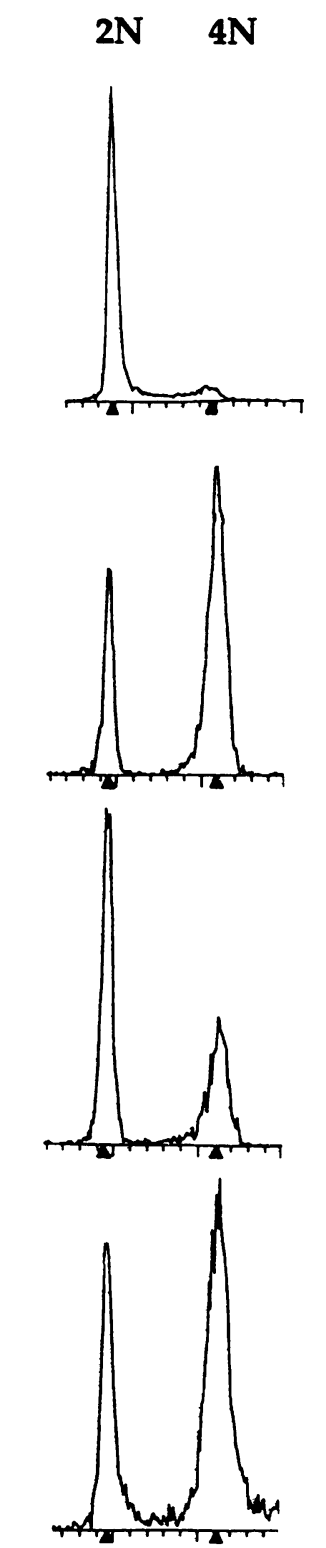

Fig. 4. Effect of FAA gene replacement on G2/M delay after MMC treatment of primary skin fibroblasts. The FA-A primary fibroblast line, PD 320, was infected with the indicated retroviral supernatants. Cells were either untreated $(A)$ or treated with MMC (25 ng/ml) for $48 \mathrm{hr}(\mathrm{B}-\mathrm{E})$. DNA flow histograms were analyzed, as described in the text. Fluorescence intensity is shown on the Y-axis and DNA content is shown on the $\mathrm{X}$-axis. The two peaks depict $2 \mathrm{~N}$ and $4 \mathrm{~N}$ DNA content.

functional protein (FAA1263delF). Interestingly, heterologous expression of the wild-type FAA protein in these cells following retroviral infection corrected MMC sensitivity (Table 1). These results confirm that EUFA007 is FA-A and suggest that the FAAdelF1263 mutant protein does not interfere with the function of the wild-type FAA protein.

\section{Discussion}

In the current study, we have used a combination of immunoblot analysis and retroviral-mediated transfer of FA genes in order to subtype FA patients. Using these methods we were able to confirm the subtype of $26 \mathrm{FA}$ patients as either FA-A, FA-C, or non-A,C.

Our results suggest that the majority of FA-A patients are missing full-length FAA protein, expressing no detectable FAA protein by immunoblot analysis. Western blot analysis with antiFAA antiserum is therefore a particularly useful screening test for identifying most FA-A patients. Although we studied too few FA-C patients to make definitive statements regarding FAC protein expression, our antibody did not show FAC protein in 5 of 6 patients, suggesting that many FA-C patients are missing full-length FAC protein. In addition, the FA-A lines all expressed FAC protein, and the FA-C lines all expressed FAA protein (Table 1). The absence of one protein does not appear to affect the stability of the other, even though FAA and FAC bind each other and form a nuclear protein complex (29). The two FA-D cell lines express both FAA and FAC proteins, as do the FA-B and FA-E cell lines (Fig. 2). Accordingly, the diagnosis of FA-A or FA-C can be accomplished in most cases by immunoblot analysis alone. Immunoblot analysis should be subsequently confirmed by retroviral infection of lymphoblast lines or primary skin fibroblasts, followed by MMC sensitivity assays.

Subtyping by immunoblot analysis is particularly advantageous for patients with FA-A, which accounts for approximately $66 \%$ of FA cases (20). Unlike FA-C, where only six mutant alleles account for most patients $(16,17)$, numerous FA-A mutant alleles have been identified (18). Most FAA gene mutations known to date $(9,10)$ result from internal deletions or truncations of genomic segments. As mentioned above, most FA-A cell lines (13/16) analyzed in this study failed to express detectable full-length FAA protein. Since the FAA gene is large, spanning 80 


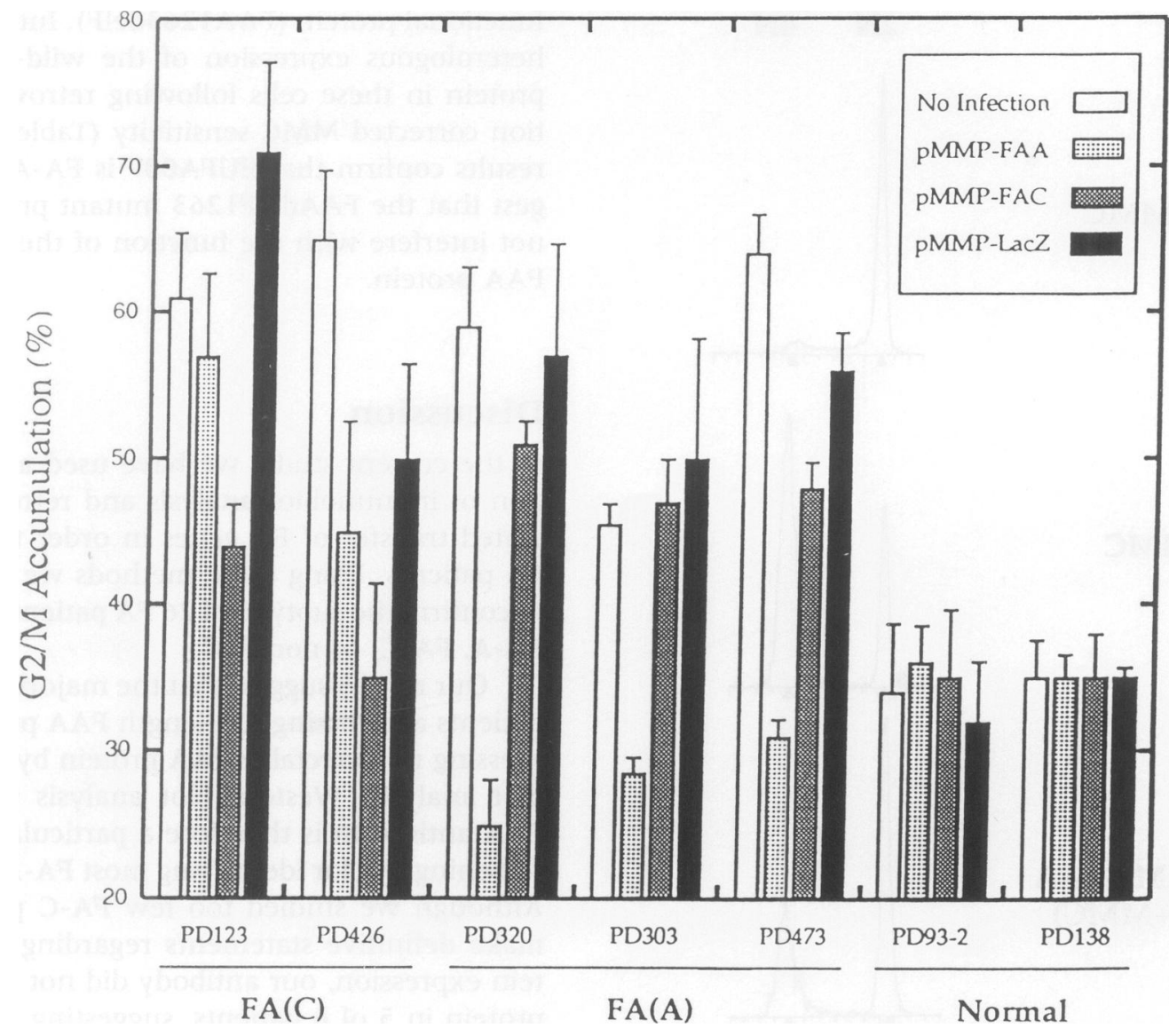

Fig. 5. Subtyping of FA primary fibroblasts by functional complementation with FA retroviruses. The indicated cell lines were infected with either no retrovirus, pMMP-FAA, pMMP-FAC, or pMMP-nlsLacZ, as indicated. Infected cells were treated with MMC (25 ng/ml) for $48 \mathrm{hr}$. Cells were stained with propidium iodide and analyzed by FACS, as described in Materials and Methods. The percentage of cells in the G2/M phase of the cell cycle was determined by analyzing data with the com-

kb (43 exons) (35), and since no common FAA mutations are known, the identification of FA-A subtypes by direct genotype analysis is more laborious than the identification of FA-C. Immunoblot analysis offers additional advantages as an adjunct to subtyping. For instance, the presence of a mutant (truncated) FAA protein can be tracked among family members of FA patients, revealing FA carrier status (M. Pulsipher, unpublished observation).

Subtyping by retroviral gene transfer is required for patients with inconclusive immunoblot results because some FA cell lines express both full-length FAA and FAC proteins. These patients are either from complementation groups puter program modFITLT. The mean values shown were calculated from three separate retroviral infection experiments. Because primary FA fibroblasts did not undergo apoptosis in response to $M M C$, we chose to study these lines by assessing G2 accumulation. In contrast, EBV-transformed lymphoblast lines undergo rapid cell death in response to $M M C$, and correction of these cells can be scored by an XTT cell survival assay (Table 1).

B, D, E, F, G, or H, or they have point mutations, small deletions, or small insertions in the FAA or FAC proteins. In these cases, specific complementation with pMMP-FAA or pMMP-FAC can not only identify a patient's subtype but also demonstrate in vitro correction of the patient's specific mutation, suggesting that the patient may be a candidate for future gene therapy trials.

On the basis of our results, we propose a sequential protocol for subtyping FA patients (Fig. 6). Initially, FA diagnosis should be made on the basis of clinical parameters and a positive DEB test. Once a diagnosis of FA is made, primary fibroblasts should be obtained and analyzed by anti-FAA and anti-FAC immunoblot. 


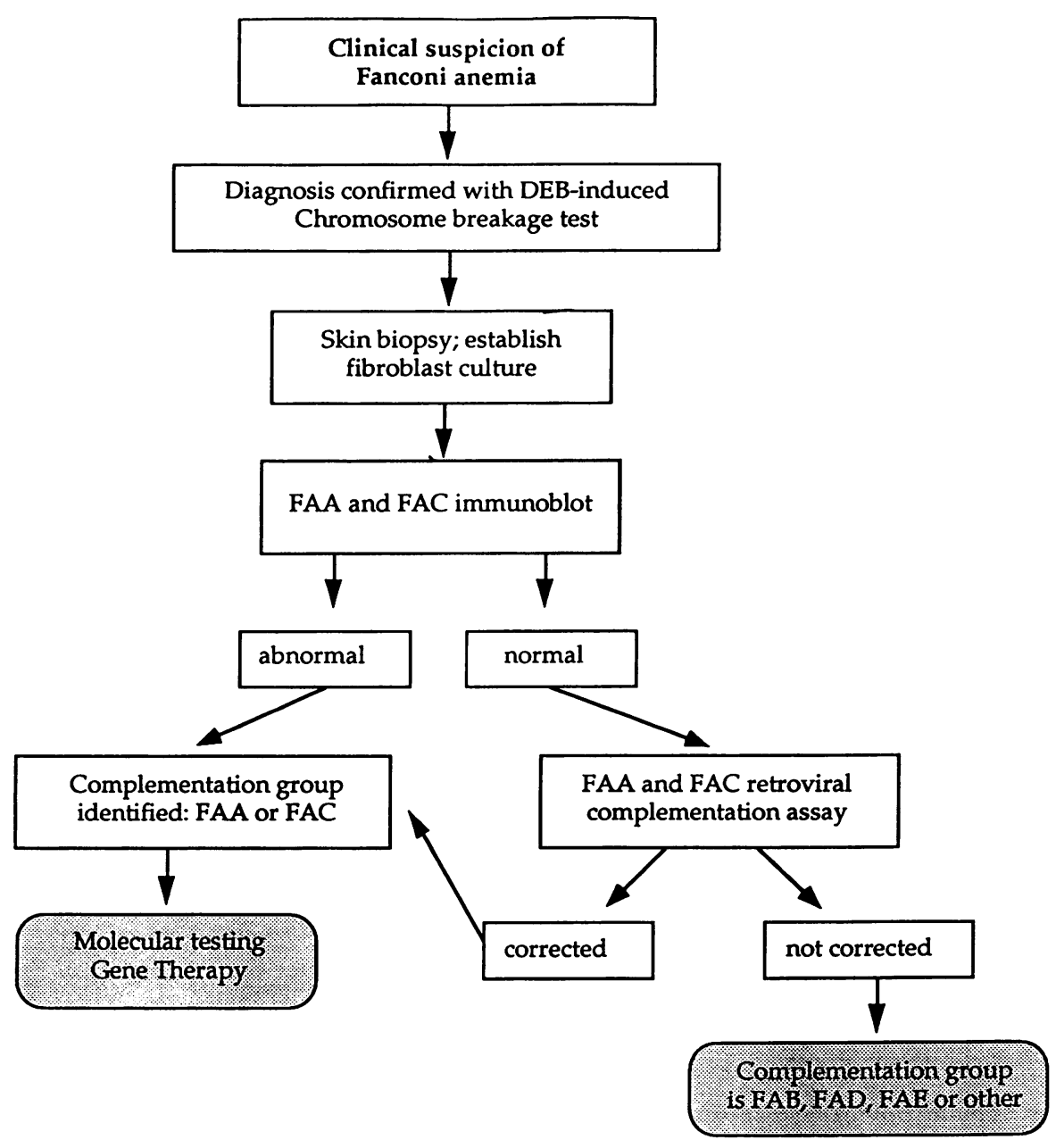

Fig. 6. Sequential protocol for subtyping Fanconi anemia patients by serial immunoblot analysis and retroviral complementation.

Patients with missing FAA or FAC proteins would be subtyped as $\mathrm{FA}(\mathrm{A})$ or $\mathrm{FA}(\mathrm{C})$ respectively, and further molecular or complementation testing could then be performed. Cells from patients expressing full-length FAA and FAC proteins would undergo retroviral complementation assays, and if corrected by FA(A) or FA(C), their subtype would be established.

While the definitive subtyping of an FA patient requires genotype analysis, the assays described in this study allow presumptive subtyping of FA and can complement other types of subtyping. This method of subtype analysis is also relatively rapid. Once a primary fibroblast culture is established (2-3 weeks) or an fibroblast or lymphoblast cell line is immortalized, the analysis takes 3 to 5 days, compared with the weeks required for genotypic analysis of FA-A or somatic cell fusion analysis. Also, direct infection of marrow progenitors can give a strong indication of subtype only 16 days after samples are obtained. For one patient (PD473), the diagnosis of FA-A was based on multiple independent criteria. First, the FA fibroblasts had no detectable FAA protein. Second, these cells were corrected by pMMP-FAA, with respect to G2/M accumulation. Third, primary bone marrow cells from this patient showed increased clonigenicity, when corrected by the $F A A$ cDNA (data not shown). The specific mutant $F A A$ alleles have not been identified for this patient.

Importantly, the false-positive and false-negative rates resulting from this method of subtype analysis are not yet known. In the current study, there was complete concordance between our subtype analysis and the more traditional methods of somatic cell fusion and direct genotype analysis (32). A large-scale prospective study of 
FA patients would be required to determine the actual false-positive and false-negative rates of our approach. Finally, the pMMP-FAA and pMMP-FAC retroviral vectors described in this study may be useful for the infection of primary FA bone marrow cells and the correction of the hematopoietic abnormality of FA by gene therapy.

\section{Acknowledgments}

This work was supported by NIH grants R01HL52725 and P01-HL54785. M.P. is supported by KO8-HLO3751-01 and G.M.K. is supported by K08-H103420. D.N. is supported by a fellowship from the Leukemia Society of America (LSA), and A.D.D. is a Scholar of the LSA.

\section{References}

1. Liu J, Buchwald M, Walsh CE, Young NS. (1994) Fanconi anemia and novel strategies for therapy. Blood 84: 3995-4007.

2. D'Andrea AD, Grompe M. (1997) Molecular biology of Fanconi anemia: Implications for diagnosis and therapy. Blood 90: 1725-1736.

3. Alter BP, Young NS. (1993) The bone marrow failure syndromes. In: Nathan DG, Oski FA (eds). Hematology of Infancy and Childhood, 4th ed., Vol 1. W.B. Saunders; Philadelphia, pp. 216-316.

4. Davies SM, Khan S, Wagner JE, Arthur DC, Auerbach AD, Ramsay NKC, Weisdorf DJ. (1996) Unrelated donor bone marrow transplantation for Fanconi anemia. Bone Marrow Transplant. 17: 4347.

5. Kohli-Kumar M, Shahidi NT, Broxmeyer HE, Masterson M, Delaat C, Sambrano J, Morris C, Auerbach AD, Harris RE. (1993) Haemopoietic stem/progenitor cell transplant in Fanconi anaemia using HLA-matched sibling umbilical cord blood cells. Br. J. Haematol. 85: 419.

6. Kohli-Kumar M, Morris C, Delaat C, Sambrano J, Masterson M, Mueller R, Shahidi NT, Yanik G, Desantes K, Friedman DJ, Auerbach AD, Harris RE. (1994) Bone marrow transplantation in Fanconi anemia using matched sibling donors. Blood 84: 2050-2054.

7. Walsh CE, Grompe $M$, Vanin E, Buchwald $M$, Young NS, Nienhuis AW, Liu JM. (1994) A functionally active retrovirus vector for gene therapy in Fanconi Anemia Group C. Blood 84: 453-459.

8. Strathdee CA, Gavish H, Shannon WR, Buchwald M. (1992) Cloning of cDNAs for Fanconi's anaemia by functional complementation. Nature 356: 763-767.

9. Lo Ten Foe JR, Rooimans MA, Bosnoyan-Collins L, et al. (1996) Expression cloning of a cDNA for the major Fanconi anemia gene, FAA. Nat. Genet. 14: $320-323$.

10. The Fanconi Anemia/Breast Cancer Consortium. (1996) Positional cloning of the Fanconi Anaemia Group A gene. Nat. Genet. 14: 324-328.

11. Fu K-L, Lo Ten Foe JR, Joenje H, Rao KW, Liu JM, Walsh CE. (1997) Functional correction of Fanconi Anemia Group A hematopoietic cells by retroviral gene transfer. Blood 90: 3296-3303.

12. Auerbach AD. (1993) Fanconi anemia diagnosis and the diepoxybutane (DEB) test. Exp. Hematol. 21: 731-733.

13. Auerbach AD, Adler B, Chaganti RSK. (1981) Prenatal and postnatal diagnosis and carrier detection of Fanconi anemia by a cytogenetic method. Pediatrics 67: 128.

14. Auerbach AD, Alter BP. (1989) Prenatal and postnatal diagnosis of aplastic anemia. In: Alter BP (ed). Methods in Hematology: Perinatal Hematology. Churchill Livingstone, Edinburgh, p. 225.

15. Shipley J, Rodeck $\mathrm{CH}$, et al. (1984) Mitomycin $\mathrm{C}$-induced chromosome damage in fetal blood cultures and prenatal diagnosis of Fanconi's anaemia. Prenat. Diagn. 4: 217.

16. Verlander PC, Lin JD, Udono MU, Q. Zhang, Gibson RA, Mathew CG, Auerbach AD. (1994) Mutation analysis of the Fanconi anemia gene $F A C$. Am. J. Hum. Genet. 54: 595-601.

17. Gillio AP, Verlander PC, Batish SD, Giampietro PF, Auerbach AD. (1997) Phenotypic consequences of mutations in the Fanconi anemia FAC gene: An international Fanconi anemia registry study. Blood 90: $105-110$.

18. Levran O, Erlich T, Magdalena N, Gregory JJ, Batish SD, Verlander PC, Auerbach AD. (1997) Sequence variation in the Fanconi anemia gene FAA. Proc. Natl. Acad. Sci. U.S.A. 94: 13051-13056.

19. Buchwald M. (1995) Complementation groups: One or more per gene. Nat. Genet. 11: 228-230.

20. Joenje $H$, Ten FL, Oostra A, Berkel CV, Rooimans M, Schroeder S, Kurth T, Wegner R, Gille J, Buchwald M, Arwert F. (1995) Classification of Fanconi anemia patients by complementation analysis: Evidence for a fifth genetic subtype. Blood 86: 2156-2160.

21. Joenje $H$, Oostra $A B$, Wijker $M$, di Summa $F M$, van berkel CGM, Rooimans MA, Ebell W, van Weel M, Pronk JC, Buchwald M, Arwert F. (1997) Evidence for at least eight Fanconi anemia genes. Am. J. Hum. Genet. 61: 940-944.

22. Whitney M, Thayer M, Reifsteck C, Olson S, et al. (1995) Microcell mediated chromosome transfer maps the Fanconi anemia group D gene to chromosome 3p. Nat. Genet. 11: 341-343.

23. Yamashita T, Barber DL, Zhu Y, Wu N, D'Andrea AD. (1994) The Fanconi anemia polypeptide FACC is localized to the cytoplasm. Proc. Natl. Acad. Sci. U.S.A. 91: 6712-6716.

24. Riviere I, Brose K, Mulligan RC. (1995) Effects of retroviral vectors design on expression of human 
adenosine deaminase in murine bone marrow transplant recipients engrafted with genetically modified cells. Proc. Natl. Acad. Sci. U.S.A. 92: 6733-6737.

25. Colicelli J, Goff SP. (1986) Isolation of a recombinant murine leukemia virus utilizing a new primer tRNA. J. Virol. 57: 37-45.

26. Ory D, Neugeboren B, Mulligan R. (1996) A stable human-derived packaging cell line for production of high-titer retrovirus/vesicular stomatitis virus $\mathrm{G}$ pseudotypes. Proc. Natl. Acad. Sci. U.S.A. 93: 11400-11406.

27. Hanenberg H, Xiao XL, Dilloo D, Hashino K, Kato I, Williams DA. (1996) Co-locolization of retrovirus and target cells on specific fibronectin fragments increases genetic transduction of mammalian cells. Nature Med. 8: 876-882.

28. Yamashita T, Wu N, Kupfer G, Corless C, Joenje H, Grompe M, D'Andrea AD. (1996) The clinical variability of Fanconi anemia (type $\mathrm{C}$ ) results from expression of an amino terminal truncated FAC polypeptide with partial activity. Blood 87: 4424-4432.

29. Kupfer GM, Naf D, Suliman A, Pulsipher M, D'Andrea AD. (1997) The Fanconi anemia proteins, FAA and FAC, interact to form a nuclear complex. Nat. Genet. 17: 487-490.

30. Moustacchi E, Papadopoulo D, Diatloff-Zito C, Buchwald M. (1987) Two complementation groups of Fanconi's anemia differ in their pheno- typic response to a DNA cross-linking treatment. Hum. Genet. 75: 45-47.

31. Strathdee CA, Duncan AMV, Buchwald M. (1992) Evidence for at least four Fanconi anemia genes including FACC on chromosome 9. Nat. Genet. 1: 196-198.

32. Jakobs PM, Fiddler-Odell E, Reifsteck C, Olson S, Moses RE, Grompe M. (1997) Complementation group assignments in Fanconi anemia fibroblast cell lines from North America. Somat. Cell Mol. Genet. 23: 1-7.

33. Kaiser TN, Lojewski A, Dougherty C, Juergens L, Sahar E, Latt SA. (1982) Flow cytometric characterization of the response of Fanconi's anemia cells to mitomycin C treatment. Cytometry 2: 291297.

34. Kubbies M, Schindler D, Hoehn H, Schinzel A, Rabinovich PS. (1985) Endogenous blockage and delay of the chromosome cycle despite normal recruitment and growth phase explain poor proliferation and frequent edomitosis in Fanconi anemia cells. Am. J. Hum. Genet. 37: 1022-1030.

35. Ianzano L, D'Apolito $M$, Centra $M$, Savino $M$, Levran $O$, Auerbach AD, Cleton-Jansen A-M, Doggett NA, Pronk JC, Tipping AJ, Gibso RA, Mathew CG, Whitmore SA, Apostolou S, Callen DF, Zelante L, Savoia A. (1997) The genomic organization of the Fanconi Anemia Group A (FAA) gene. Genomics 41: 309-314. 